\title{
Advance decisions, dementia and subsequent inconsistent behaviour: a call for greater clarity in the law.
}

CHRISTIE, S.

2019 
Advance decisions, dementia and subsequent inconsistent behaviour: a call for greater clarity in the law

Dr Sarah Christie, Academic Strategic Lead, The Law School, Robert Gordon University

The Law School

Robert Gordon University

Garthdee Road

Aberdeen

AB10 7QE

s.christie@rgu.ac.uk

Word count - 5273 


\section{Advance decisions, dementia and subsequent inconsistent behaviour: a call for greater clarity in the law}

This paper considers the interpretation of section $25(2)(c)$ of the Mental Capacity Act 2005, on the relevance of subsequent inconsistent behaviour by the maker of an advance decision. Consideration of the very few cases, and analysis of how existing rules of statutory interpretation could be applied, identifies a particular problem in relation to those who appear to contradict their own prior decision, but do so after they have lost capacity. This highlights an issue which has already been raised in the philosophical literature where there has been some discussion of the relevance and moral authority of our own prior decisions over our future selves, particularly where our future self appears content with a situation which would have been intolerable to our prior self. The incidence of cases of this type is not confined to the realms of philosophy; indeed these kinds of situations are likely to increase, given predictions of the rise in cases of dementia over the next 30 years, and so we will require an unambiguous legal framework to deal with assessing the validity of an individual's advance decision, and the ramifications of acting upon it. The law, as currently stated, is not clear in respect of these types of cases, and should be revised to provide clarity, and with it the greater confidence and uptake in advance planning desired by central government. 
Keywords:

Advance decisions, capacity, dementia, contradictory statements, statutory interpretation.

\section{Advance Decisions, capacity and future decision-making}

“...exceptionally difficult moral, legal and ethical questions ... may

have to be addressed when a previously competent patient is in the 'twilight' position of having lost his capacity to decide whether or not to accept medical treatment but nonetheless remains able, to a greater or lesser extent, to express his wishes and feelings. Is such a patient to be held to his advance directive even if it appears to conflict with his current (incompetent) wishes and feelings?"1

Advance decisions ${ }^{2}$ have existed, with the force of law in England and Wales, for some time, and are designed to allow individuals to set out in advance their decisions about their own future treatment, should they be incapable of expressing themselves when the time comes. However, they are not without their controversies. A

\footnotetext{
${ }^{1}$ HE v. A Hospital NHS Trust [2003] EWHC 1017 (Fam) at para 38, fn 2 (per Lord Munby).

${ }^{2}$ Variously referred to as advance decisions or advance directives, but for the sake of consistency and clarity, I shall use the term "advance decisions" throughout.
} 
contradictory action or statement by an individual made after they have drawn up such a document poses particular problems, and is the situation both alluded to above by Munby J., and (perhaps) resolved by s25(2)(c) of the Mental Capacity Act 2005. However, I will argue that while this section may be satisfactory in cases such as HE quoted above, the underlying issue will present itself in other situations (specifically where the person exhibiting contradictory behaviour has now lost mental capacity). There is as yet little case law on the matter to help to cast light on the application of the section and since, as I will show, situations involving incompetent contradictory behaviour are not so readily addressed by the existing legislation, the wording of the relevant provision should be reconsidered.

Advance planning has become an increasingly important part of medical, legal and social practice as individual autonomy has become more firmly entrenched, and as life expectancy increases. With this increase in average life expectancy has come an increase in conditions which are more prevalent in old age, in particular incidences of dementia. Alzheimer's UK estimates over a million people will suffer with dementia by 2025 , and two million by $2051^{3}$, making it a major health priority. Dementia has particular relevance

\footnotetext{
${ }^{3}$ Alzheimer's Society, Dementia UK report, http://www.alzheimers.org.uk/info/20025/policy_and_influencing/251/dementia_ uk
} 
for issues of capacity and decision-making in law, and the extent to which an individual's treatment decisions should be followed, particularly when an individual loses capacity because of dementia, and makes inconsistent and contradictory statements or behaviours which appear to fly in the face of their own advance decision. Although section 25(2)(c) exists, it has been subject to very little judicial comment, and none specifically in relation to the problem highlighted by Munby J above. However, given the figures just quoted on the predicted rise in cases of dementia over the next 30 years, the incidence of legal disputes relating to dementia and decision-making will only increase, and the law should be better prepared to deal with it.

It has for some time now been accepted that a competent adult's decision in respect of their own treatment is sacrosanct, and a line of authorities now point to the absolute respect which must be granted to the autonomous adult's decision to refuse treatment. ${ }^{4}$ The Mental Capacity Act $2005^{5}$ puts onto a statutory footing the concept of an advance decision, whereby a competent individual can set out their decisions to refuse specific future treatment options,

\footnotetext{
${ }^{4}$ See Re B (Adult, refusal of medical treatment) [2002] 2 All ER 449, and St. George's Healthcare NHS Trust v S; R v Collins and others, ex parte S [1998] 3 All ER 673. This includes an anticipatory refusal of treatment - see HE v NHS Trust A and AE [2003] EWHC 1017 (Fam)

${ }^{5}$ Sections 24 to 26, applicable to England and Wales only. Hereafter referred to as the MCA.
} 
should particular circumstances arise after they have lost capacity ${ }^{6}$. On its introduction, the Government expressed their expectation that the Act would bring about "a quiet revolution in public attitudes and practice"7. However, while there is scope for this to have some impact in the arena of decision-making for those who are no longer competent, the incidence of use of such documents is relatively low. The British Social Attitudes Survey in $2012^{8}$, when considering death and dying, noted that while $70 \%$ of respondents said that they felt comfortable talking about death ${ }^{9}$, fewer than $5 \%$ had indicated that they had a "living will" (i.e. an advance decision). This shows that the reported level of comfort with the topic of death did not lead to an equally high rate of reported discussions about death and end of life wishes, much less the formalising of this into a documentary statement of those wishes ${ }^{10}$.

\section{The problem of diminishing capacity}

Beyond the issue of uptake and usage by individuals, there are other aspects of advance decisions which remain controversial. The premise behind the law set out in the MCA is that the autonomous

\footnotetext{
${ }^{6}$ For example, an individual could use an advance decision to state that, in the future, if diagnosed with a terminal condition, and if unable to make or communicate their wishes in relation to life sustaining treatment, they do not wish such treatment to be started.

${ }^{7}$ HC Deb 4 July 1996, vol 280, col 68WS, per David Lammy.

${ }^{8}$ British Social Attitudes Survey 30 (2012) http://www.bsa.natcen.ac.uk/media/38850/bsa_30_dying.pdf 9 Ibid., p1.

10 Ibid., p14.
} 
decision of a competent adult is sacrosanct. In end of life issues, timelines and trajectories are seldom simple, and the blunt facts show that many adults will approach the end of life phase in a state of declining mental capacity, if not having already lost capacity. In such cases, it is notoriously difficult to predict the onset of a loss of capacity, and often that loss will not be exemplified in a single cataclysmic event during which the individual moves from having capacity, to losing capacity completely. Instead, capacity will gradually dwindle as the effects of dementia increase and so the individual's capacity will manifest itself as a sliding scale. But once capacity is finally lost, so also goes autonomy, and therefore the ability for them to make any further decisions about medical treatment at that point in time. The purpose of advance decisions is to allow for this decision to have been taken earlier, at a time when they still had capacity. In doing so, it forms part of the concept of advance care planning, and further enables the pendulum-swing away from paternalism and towards person-centred care, and autonomous decision-making by the individual themselves. However, the nature of dementia is such that its effect on the individual can last for a considerable period, moving through phases as it increases in severity, and that the individual will retain the capacity to communicate, in some cases right to the end. With this come some thorny issues which require to be addressed, in particular the status of any statement made by the individual, after 
they have lost capacity, which appears to contradict the essence, or indeed the substance, of their own earlier advance decision. This might, for example, come in the form of an expression of a determination to survive which contradicts an earlier advance decision rejecting life sustaining interventions once their condition had deteriorated beyond a certain point. As the incidence of dementia rises, the number of individuals in these situations will also increase, and we will require an unambiguous legal framework to deal with assessing the validity of an individual's advance decision, and the ramifications of acting upon it.

Borrowing for a moment from the well-known case of Margo ${ }^{11}$, as further discussed by Dworkin ${ }^{12}$, difficult issues arise in respect of those gradually losing first capacity, and then more general abilities as a result of conditions such as dementia. Margo's case is the subject of considerable discussion in the ethical and philosophical literature, but the scenario identified by Firlik is one which will resonate with many who have experience of caring for those with advancing dementia. Firlik describes his contact with Margo in some detail, and in doing so, highlights some of the core problematic issues raised by dementia. He reports that she says she enjoys

\footnotetext{
${ }^{11}$ A. Firlik, “Margo's Logo" 265 (1991) J ournal of the American Medical Association 201.

12 R. Dworkin, Life's Dominion: an argument about abortion, euthanasia and individual freedom, New York. Random House. 1993 at p220.
} 
reading books, but her bookmark jumps around from one random place in the book to another with no recollection of what page she has already read to; that she paints, but repeatedly paints the same abstract picture; that she professes to remember him when he visits but never uses his name; and that she still clearly derives enjoyment from aspects of her life; specifically lunchtime peanut butter and jelly sandwiches. ${ }^{13}$ The picture he presents, which is common among such patients, is one of a continuing decline from early stage dementia through to more advanced phases, characterised by increasing loss, over time, of memory, understanding and the ability to reason. The early stages are often marked by gradually increasing problems with short-term memory, confusion and difficulty planning or deciding. As the disease progresses, problems with memory loss and forgetfulness become more significant, and are often accompanied by elements of aggression, emotional distress, anger and agitation. Later stages of the disease are marked by issues such as profound memory loss, dependency on others, and significant difficulties with aspects of personal care ${ }^{14}$.

\footnotetext{
13 ibid., at p221.

14 Alzheimer's Society, "How dementia progresses" available at https://www.alzheimers.org.uk/info/20073/how_dementia_progresses/1048/the progression_of_alzheimers_disease_and_other_dementias/3
} 
Now imagine a situation where an individual makes an advance decision, stating that if they have lost capacity and have subsequently been diagnosed with cancer, they do not want any life-saving or life-sustaining treatment because they view life without competence, capacity and memory as intolerable and would not wish to go through intensive treatment for cancer in order to prolong their life with dementia. In the intervening years, they have made statements to family members and their GP, which are consistent with this remaining their clear decision. They are later diagnosed with dementia, and go into rapid decline, requiring them to move into a care home. Over time, it becomes clear that the dementia has taken hold to the extent that they have lost capacity, and require full personal care, and they have also been diagnosed as suffering from cancer. While it is true that they are suffering from a serious but treatable condition, it is also clear that they still enjoy aspects of daily life and in conversations with family and staff, have verbally expressed contentment with their situation. At no point while they retained capacity, did they revoke their advance decision. So, should they need life-saving or life-sustaining measures, what takes precedence - their earlier advance decision, drawn up while they had capacity, or their more recent expressions of happiness with their current situation, made after the loss of capacity? The crucial question becomes that of the effect of those apparently contradictory statements made in the grip of dementia. 


\section{The philosophical perspective}

While the law sets out criteria for validity, and asserts the primacy of advance decisions where they are valid and applicable to the circumstances, there remains debate about subsequent apparently contradictory statements in situations such as dementia, and what effect those statements have. Without diving too deeply into the philosophical underpinnings, it is worth highlighting briefly where different schools of thought stand on the concept of the prior authority of an earlier version of oneself. Dworkin asserts the significance of precedent autonomy, and gives the competent prior self's interest in exercising autonomy precedence over any interests of the later incompetent self. He does so under an integrity view of autonomy, whereby what is respected and upheld is the competent individual's sense of the shape and type of life they want to live out $^{15}$. He distinguishes critical and experiential interests, and gives critical interests (hopes, beliefs, values) greater moral significance than experiential interests (things we do because we enjoy the experience of them $)^{16}$. Advance decisions setting out how that individual wants to live out the rest of their life, in a way which reflects their consistent belief in a life of value to them, conform to those critical interests, and therefore (on the grounds of precedent

${ }^{15}$ Dworkin, op.cit., pp224-6.

16 Ibid., p201ff 
autonomy) have authority and determine what happens to the individual in those circumstances, once they have lost capacity.

In this context, and contrary to Dworkin's position, the concept of psychological connectedness or continuity is often used to assert that the person who makes the advance decision, and the later version of themselves who develops dementia, are insufficiently connected to allow for the decision to carry authority over that later person and determine what happens to them ${ }^{17}$. The psychological links between the different phases of our lives which link us into one continuing "person" include aspects such as memories, desires and beliefs, all of which fall by the wayside as dementia progresses. The argument put forward is that, once dementia takes hold, the person in question no longer has the same interests as the person who made the decision, or even that they are no longer the same person. This, it is argued, robs the advance decision of its moral authority, and that therefore any attempt to uphold an earlier decision to do something as critical as withholding life-sustaining treatment, cannot be carried out. Writers such as Robertson ${ }^{18}$ state that the values which underpin the advance decision taken prior to

\footnotetext{
17 On this, see writers such as D. Parfit, Reasons and Persons, Oxford, OUP, 1986 at pp206-7, and R. Dresser, "Dworkin on Dementia: Elegant Theory, Questionable Policy" in Kuhse, H., and Singer, P. (eds), Bioethics: an anthology, Oxford, Blackwell, 1999, p312.

18 J. Robertson, "Second Thought on Living Wills" 21(6) 1991 Hastings Center Report 6 at p7.
} 
the onset of dementia, no longer hold any place in the life of a person for whom those values no longer resonate, and that the shift from competence to incompetence is so radical that the focus must be on the individual's interests now, as an incompetent person, not their prior advance decision. He does however assert that the person in question is still the same person, but with different interests.

However, this is not the place to delve too far into these arguments. The MCA enshrines advance decisions into law. The issue here is the manner in which it does so, and the phrasing of particular sections which pose some difficult questions.

\section{A legal response - the words in the Act}

Section 24 of the MCA sets out the establishing principle that someone over 18 with capacity can reject specified treatment for themselves in the future, provided that the circumstances envisaged in the advance decision have arisen, and providing that they have, by that point in the future, lost capacity. Should such criteria be met, then the relevant treatment should not be undertaken. This is a clear statement of the nature and extent of the influence of autonomy. It allows a situation whereby an individual can envisage potential future circumstances and, depending on their values and beliefs, provide clear instructions in 
advance to resolve the difficulty which would otherwise be faced; the need for proxy decision making, potentially life and death decision making, in the individual's best interests. Since the purpose of an advance decision is that it should apply at some point in the future, it is designed to be a document with some, perhaps considerable, longevity. This raises the issues of its continuing validity. Like all documents drawn up by a competent individual, it cannot operate to tie the hands of its maker while they retain capacity. There is always the scope for that individual to alter or entirely revoke the advance decision. This is set out in section 25(2) which reads thus

\section{s25 Validity and applicability of advance decisions}

(2) An advance decision is not valid if $\mathrm{P}_{-}$

(a) has withdrawn the decision at a time when he had capacity to do so,

(b) has, under a lasting power of attorney created after the advance decision was made, conferred authority on the donee (or, if more than one, any of them) to give or refuse consent to the treatment to which the advance decision relates, or (c) has done anything else clearly inconsistent with the advance decision remaining his fixed decision. 
While this subsection purports to set out criteria under which an individual can effectively nullify their own previous advance decision, there is a potential problem with the construction of s25(2)(c). If we cast our minds back, for a moment, to the hypothetical situation outlined above, that individual was apparently content in the care home, enjoyed aspects of their daily life, and had verbally expressed that contentment. Would this amount to something which meets the criteria set out in s25(2)(c)? A close look at the criteria set out in s25(2) shows some variation in the style of expression, but there is a key shared factor which applies to, at least parts (a) and (b). S25(2)(a) explicitly classifies an advance decision as invalid if the person who made it has withdrawn it at a time when they had capacity to do so. Thus a key criterion for rendering a decision invalid is capacity. Part (b) does not explicitly use the term "capacity" but refers instead to a situation where the person who made the advance decision subsequently grants a lasting power of attorney which empowers the donee to consent or refuse to consent to the same specified treatment as covered by the decision. Clearly this would invalidate the earlier advance decision as the person would have made other, specific provisions for decision-making on that issue in the future. ${ }^{19}$

\footnotetext{
19 On this point, see Re E [2014] EWCOP 27, paras 43-50, where an individual's advance decision became effective before her lasting power of attorney was recorded and became effective. The effect of this was that her lasting power of attorney, coming later, invalidated her previous advance decision, although the
} 
The donee would be given the authority to decide on that particular treatment if the person themselves is, by then, incapable of deciding themselves. However, part (b) does share with part (a) that same key criterion of capacity. Although not mentioned specifically, the granting of a lasting power of attorney is an act which requires capacity, and so the act which invalidates the advance decision (the grant of that power) is also an act which requires that the person still retains capacity.

So, in terms of interpreting the scope of s25(2), the means by which an advance decision can be withdrawn by the person who made it encompass two situations which clearly require that the person still has capacity. Those means of withdrawing an advance decision cannot be undertaken after the person has lost capacity as a result of, for example, advancing dementia. Thus, once that person has lost capacity, they remain bound by the terms of that decision, and by any refusal of treatment contained in it. The more problematic issue is $s 25(2)(c)$, which again does not explicitly mention capacity, but also does not, at least on the face of it, encompass a situation which automatically requires capacity before it could come about. Part (c) provides that an advance decision is not valid if the person has done anything else clearly inconsistent 
with it remaining their fixed decision. The term "anything else" is less clear that it might be. Does it mean "anything else at all", or (like parts (a) and (b)) is it constrained by the concept of capacity and does it therefore mean "anything else while they retained capacity"?

The implications of this are stark. To return again, for a moment, to our earlier example, the real crux of the issue here is the relevance of those statements made by the person, after they have lost capacity, which appear to contradict the terms of the advance decision. What effect, if any, must be given to them? If the first interpretation is correct, then the contradictory statements made after they lost capacity overrule the earlier advance decision. If the latter interpretation is taken, then the contradictory statements are not given any effect and the earlier advance decision stands.

\section{The meaning of the words in the Act}

With a question about the scope and application of $s 25(2)(c)$ in mind, we can now turn to the rules on statutory interpretation and other guides, to see if this can cast any further light on its meaning. There are a well-known set of rules of statutory interpretation, which begin with an acknowledgment that the first port of call should be the plain ordinary meaning of the provision. It is only if that meaning is contrary to the purpose of the statute and the 
intention of Parliament, that further work is required. The plain, ordinary meaning of $s 25(2)$ (c) could be argued to be "done anything else at all", and since the purpose of the MCA, as identified in the Code of Practice, is to allow individuals to make preparations for a time when they will lack capacity in the future, it would seem that the plain, ordinary meaning runs contrary to the purpose of the statute.

Statutory language must be interpreted in its context, as was made clear in Attorney-General v. Prince Ernest Augustus of Hanover ${ }^{20}$ where Viscount Simonds held that “...words, and particularly general words, cannot be read in isolation; their colour and their content are derived from their context". This finds expression in the noscitur a sociis rule which specifies that general words (and here I would contend that "anything else" is sufficiently general to fall under this) are to be coloured and shaped by their context, and by that with which they are associated. By virtue of being grouped under a single subsection, and being clearly designated as three means by which an advance decision will not be valid, it would suggest that the constituent parts of section 25(2) are all associates of each other. In s25(2), both parts (a) and (b) provide a particular kind of context; acts by which a person can render their own earlier

20 [1957] AC 436 at p461. 
advance decision invalid, and specifically, acts by which a person who has capacity (and only a person with capacity) can so render. Since part (a) specifies capacity and part (b) cannot be achieved without capacity, this then raises the implication that, following the noscitur rule, part (c) takes its colour and shape from that same context. In other words, that the noscitur rule requires part (c) to be interpreted as meaning "any other act done while that person retains capacity". But that is not the only guide we can consider here. The eiusdem generis rule also states that subsequent general words or phrases are to be understood in the context of more specific words, such that general words appended to the end of a list of specifics, sharing a particular element, are construed in the light of that shared element. So, classically speaking, a phrase such as "eggs, milk, cream and other foodstuffs" includes butter, but not bread. Again, here, this can be used to interpret part (c) as being confined to other acts also done while the person retained capacity, since that is the shared criterion which is common to both part (a) and part (b). The purpose of the eiusdem generis rule is to identify where there is a series of things expressed in a statute which can be identified as species within a genus; that is to say, identifiable things recognised as belonging to a broader category. It then follows that subsequent general words are to be interpreted as also 
belonging to that same genus. ${ }^{21}$ The statutory series which can be identified here is of two instances in $s 25(2)(a)$ and (b), of 'things requiring capacity' (the genus) and thus the general words which follow in s25(2)(c) should also be construed in the same way. The application of this rule is, however, subject to the court's duty to have regard to the purpose of the statute and thus, if the purpose of the statute required the general words which followed, to be interpreted more widely than the identified genus, the eiusdem generis rule is defeated. The purpose of the MCA is expressed in the Code of Practice in the following terms. It “...provides a statutory framework for people who lack capacity to make decisions for themselves, or who have capacity and want to make preparations for a time when they may lack capacity in the future"22. If the eiusdem generis rule were not applied, and part (c) were given its widest meaning (anything at all done at any time, before or after the loss of capacity), then this would allow apparently contradictory statements made after the loss of capacity to undermine the precise purpose of the MCA, as such statements would prevent the instigation of the very measures the individual had put in place

\footnotetext{
${ }^{21}$ See J. Bell and G. Engle, Cross on Statutory Interpretation, $3^{\text {rd }}$ edn, Butterworths, London, 1995 at pp135-7, and Attorney-General v. Brown [1920] 1 KB 773.

22 Mental Capacity Act 2005 Code of Practice, p1, available at https://assets. publishing.service.gov.uk/government/uploads/system/uploads/att achment_data/file/497253/Mental-capacity-act-code-of-practice. pdf.
} 
some time previously, in order to deal with a future onset of incapacity.

Rules of statutory interpretation also require that a statute is read as a whole, looking at all other parts of the Act, and here we find statements such as that in s24(3) ("P may withdraw or alter an advance decision at any time when he has capacity to do so"). The Explanatory Notes to the Act do not cast any light on the interpretation of part (c) in this context, as they focus on examples taken from existing case law, such as that of the Jehovah's witness who made an advance decision rejecting blood products of all types, and subsequently rejected that faith, converted to Islam and married in that new faith. While these were clearly evidence of having done "anything else" which indicated that she viewed her advance decision as no longer her fixed decision, these remain acts which she carried out while retaining full capacity, and so can be distinguished from the kind of problem case we are considering. The Mental Capacity Act Code of Practice gives an example of a part (c) type situation by envisaging someone who makes an advance decision to refuse particular treatment and then later specifically gives their competent consent for that same treatment. ${ }^{23}$ Indeed,

\footnotetext{
23 Mental Capacity Act 2005 Code of Practice p170, available at https://assets. publishing. service.gov.uk/government/uploads/system/uploads/att achment_data/file/497253/Mental-capacity-act-code-of-practice.pdf.
} 
the example given in the Code of Practice specifically refers to someone making a contradictory statement (authorising treatment in the face of the advance decision), while they still retained capacity and so casts no further light on the situation envisaged here. The evidence points towards finding that the purpose behind the provisions here is to empower those who choose to do so, to make advance decisions which will be binding at a later date if they meet the requirements for validity and applicability. To allow for a situation where a condition which will affect so many in their later years, and which is characterised by a loss of capacity and therefore the potential for making contradictory statements without legal capacity, to invalidate an advance decision seems to defeat the purpose of the provisions in ss24-26. This is borne out in In re Briggs (Incapacitated Person) (Medical Treatment: Best Interests Decision) (No 2) ${ }^{24}$ where, in a brief discussion of section 25(2)(c), Charles J notes that the section does not specify whether capacity is required at the time of the inconsistent behaviour. He goes on to state that if the section was indeed meant to set a low threshold and make it easy to invalidate an advance decision, favouring preservation of life over prior competently-expressed decisions, that would run contrary to the intention of the MCA in respect of advance decisions.

24 [2016] EWCOP 53 at para 22. 


\section{A note of considerable caution}

This would all seem to point to an interpretation of part (c) as meaning "has done anything else while they retained capacity which is clearly inconsistent with the advance decision remaining their fixed intention". However, the addition of the section in italics is not without its own problems. Whether or not it can be said that the application of long-standing and accepted aids to statutory interpretation mean that any other contradictory act or statement by the person is only effective in invalidating the previous advance decision if the person still has capacity, the implications of this are fairly stark.

Such an interpretation would involve taking someone like Margo, or the person we envisaged at the outset of this piece, acknowledging their current state as one in which, despite having been robbed of their capacity, they are apparently content and have verbally or non-verbally expressed this, and then denying that there is any effect flowing from their current contented situation. This would be contentious, as the advance decision would still be viewed as operative, and should the situation envisaged and provided for in the decision materialise, the advance decision should determine that treatment is not offered or is discontinued. Thus the individual, apparently content with their current situation, would be denied 
potentially life-saving treatment for their cancer, and may therefore die sooner, because their advance decision stands.

The difficult position which s25(2) leaves us in is that it, along with ss24 and 26, is clearly designed to allow those who choose to do so, the means to give effect to their beliefs and values, and their autonomous right to choose for themselves in the future when they have become incapacitated. And yet $s 25(2)$ sets up an internal contradiction; interpreted solely on the basis of the plain meaning of the words used, part (c) defeats that purpose by requiring the advance decision to be rendered invalid by expressions which contradict the terms of the decision, made after capacity has been lost. This means, to put it bluntly, that anything done by the person after the loss of their capacity can derail the purpose of the advance decision which was made while they had capacity, to provide a clear, competent, value-driven decision to stand in the place of their own later incapacity. On the other hand, to interpret part (c) using the aids to construction, instead of its plain ordinary meaning, means that clinical teams, family and friends are faced with a situation where expressions of contentment by the person for whom they care, and whom they love, are disregarded in the face of the prior authority of the advance decision. In practical terms, this is an unenviable choice but one which the law as currently expressed does nothing to clarify. 


\section{Concluding thoughts and a call for (more) clarity}

Where then does this leave us? As currently expressed, a plain meaning interpretation of the law in section 25(2)(c) allows a contradictory statement made by someone who has lost capacity, to override the validity of their earlier advance decision. No-one would wish to suggest that in the kinds of circumstances envisaged in this discussion, any expression of current wishes which ran contrary to the terms of an advance decision, should be completely disregarded, particularly where the current statement is one expressing contentment and a desire to continue living, while the advance decision dictates, for example, the refusal of heroic lifesaving treatment. Indeed, in the context of decision-making on the basis of best interests under section 4 of the Act, both past and present wishes and feelings are to be taken into account in utilising the balance sheet approach to best interests (although how one proceeds with this balancing exercise when past and present wishes are contradictory is another question). The language of the law is, however, unhelpful in section 25(2)(c). The purpose of sections 24 to 26 of the MCA is to allow for patient autonomy and selfdetermination, and for decision-making in respect of treatment to be vested in the hands of the individual themselves, who is able to refuse future treatment, if they choose to create a valid advance decision. The language used in section 25(2)(c) - that an advance 
decision is not valid if the individual has done anything else clearly inconsistent with the advance decision remaining his fixed decision - avoids specifying whether the inconsistency has to arise before the loss of capacity takes hold. It appears on the face of it to allow for inconsistent statements made both before and after the loss of capacity to have this invalidating effect, but without stating as much in explicit terms. Given the significance of this interpretation of section 25(2)(c), absolute clarity would be more helpful. If it is designed to allow incompetent contradictory statements to invalidate the earlier autonomous decision of the individual, then it should say so explicitly. If it is not so intended, then it should equally explicitly state the continuation of precedent autonomy and the fact that the prior advance decision stands, regardless of the contradictory statements if they arise after the onset of incapacity. In determining which interpretation should be taken, an underlying decision is necessary. If the individual, once they have lost capacity, makes no contradictory statements, we need to decide whether we are prepared to see their precedent autonomy, exercised through the existence of an advance decision, carried through. The existence of ss24-26 of the MCA suggest that, as a society, we are accepting of this principle. If the individual who has lost capacity does make contradictory statements, we have to decide whether we are prepared to still uphold that precedent autonomy expressed through the advance decision, and disregard those statements, or whether 
we would instead view the existence of those contradictory statements as something which overrides precedent autonomy, and is a trigger for best interests decision-making.

If the latter route is the one we, as a society, would prefer to take, then it requires greater clarity in the law. As it stands, the purpose behind this part of the MCA is the promotion of patient autonomy, including making decisions for their own future. If we take the latter interpretation of $s 25(2)(c)$, then we dilute that autonomy by allowing statements made after the loss of capacity to override the individual's own advance decision. Whichever way we wish to proceed, the wording of the section is not helpful in its lack of clarity as to whether the context (that of an individual with capacity) covers all three subsections, or only the first two.

\section{A recommendation}

I would suggest that, before the Act can effect the "quiet revolution" in advance care planning envisaged by the Government, greater attention needs to be paid to the precise construction borne by specific sections, and that section $25(2)(c)$ should explicitly state when such inconsistent acts should have taken place in order for them to invalidate the advance decision. The re-phrasing of section $25(2)(c)$ to read "has done anything else while they retained capacity, which is clearly inconsistent with the advance decision 
remaining his fixed decision" would clarify the position, and would allow individuals to be absolutely clear about the long-term implications of their advance decision for their own care. This, in turn, would lead perhaps to both a greater public confidence in such documents, and greater uptake, both of which are clear priorities in the increasing pressing area of elder care and end of life medicine. The law both can, and should, play its role in helping to achieve over-arching goals, and in this particular situation, can do so by adopting a legal framework which is more robust and explicit, in advance of such cases becoming increasingly prevalent as the population ages disproportionately, and dementia cases rise as predicted. 